\title{
The histone deacetylase inhibitor trichostatin A alters microRNA expression profiles in apoptosis-resistant breast cancer cells
}

\author{
LYNDSAY V. RHODES ${ }^{1}$, ASHLEY M. NITSCHKE ${ }^{1}$, H. CHRIS SEGAR ${ }^{1}$, ELIZABETH C. MARTIN ${ }^{1}$, \\ JENNIFER L. DRIVER ${ }^{1}$, STEVEN ELLIOTT ${ }^{1}$, SEUNG YOON NAM ${ }^{6}$, MENG LI $^{6}$, KENNETH P. NEPHEW $^{6}$, \\ MATTHEW E. BUROW ${ }^{1,2,4,5}$ and BRIDGETTE M. COLLINS-BUROW ${ }^{1,4,5}$ \\ Departments of ${ }^{1}$ Medicine, Section of Hematology and Medical Oncology, ${ }^{2}$ Pharmacology and ${ }^{3}$ Pathology \\ and Laboratory Medicine, ${ }^{4}$ Center for Bioenvironmental Research, ${ }^{5}$ Tulane Cancer Center, Tulane University \\ Health Sciences Center, New Orleans, LA 70112; ${ }^{6}$ Medical Sciences and Department of Cellular and \\ Integrative Physiology, Indiana University School of Medicine, Bloomington, IN 47405, USA
}

Received July 13, 2011; Accepted August 29, 2011

DOI: $10.3892 /$ or.2011.1488

\begin{abstract}
The development of drug resistance represents a major complication in the effective treatment of breast cancer. Epigenetic therapy, through the use of histone deacetylase inhibitors (HDACi) or demethylation agents, is an emerging area of therapeutic targeting in a number of ontological entities, particularly in the setting of aggressive therapy-resistant disease. Using the well-described HDAC inhibitor trichostatin A (TSA) we demonstrate the suppression of in vitro clonogenicity in the previously described apoptosis-resistant MCF-7TN-R breast carcinoma cell line. Additionally, recent work has demonstrated that these agents can alter the expression profile of microRNA signatures in malignant cells. Using an unbiased microRNA microarray analysis, changes in miRNA expression of MCF-7TN-R cells treated with TSA for $24 \mathrm{~h}$ were analyzed. We observed significant up-regulation of 22 miRNAs and down-regulation of 10 miRNAs in response to TSA treatment. Our results demonstrate that the HDACi, TSA, exerts anticancer activity in the apoptosis-resistant MCF-7TN-R breast carcinoma cell line. This activity is correlated with TSA alteration of microRNA expression profiles indicative of a less aggressive phenotype.
\end{abstract}

\section{Introduction}

Despite significant advancement in the area of endocrine therapies and chemotherapeutics, nearly half of breast cancer patients exhibit de novo resistance, while the majority of

Correspondence to: Dr Bridgette M. Collins-Burow, Tulane University Health Sciences Center, Department of Medicine, 1430 Tulane Ave. SL-78, New Orleans, LA 70112, USA

E-mail: bcollin1@tulane.edu

Key words: microRNA, trichostatin A, histone deacetylase, MCF-7, breast cancer, drug resistance remaining patients ultimately progress to drug resistance (1). Drug resistant breast cancer is associated with poor prognoses $(2,3)$, highlighting the critical need to develop novel therapeutics that are effective against these more aggressive forms of the disease. Epigenetic alterations, including aberrant DNA methylation and histone deacetylation, participate in cancer development and progression (4). Epigenetic aberrations lead to breast cancer chemotherapy resistance $(5,6)$; hence, their reversal by inhibitors of DNA methylation and histone deacetylases (DNMTi and HDACi) may overcome it and are at present undergoing clinical testing, either alone or in combination with conventional chemotherapies (7).

Histone deacetylases (HDACs) and histone acetyltransferases (HATs) have important roles in the maintenance and function of chromatin by regulating the acetylation of histones. In addition, these enzymes have recently been shown to regulate the acetylation of many non-histone targets and therefore may represent a key means of post-translational regulation beyond their established roles in transcriptional regulation. The use of HDACi in the clinical setting is currently FDA-approved only for the treatment of progressive or recurrent cutaneous T-cell lymphoma following two other systemic therapies (8). Biologically, HDACi induce growth arrest, differentiation and cell death in breast cancer cells, but the underlying mechanism warrants further investigation.

In addition to direct regulation of mRNA gene expression, HDACis have been shown to alter microRNA (miRNA) expression in several human carcinomas including pancreatic (9), colon (10,11), gastric (12) and breast (13). microRNAs are small non-coding RNAs (18-22 nt) which function as an additional layer of regulation of mRNA stability and translation through 3'-UTR targeting (14). Through their ability to target the 3'-UTR of multiple genes, individual miRNAs can exert vast effects on mRNA-protein expression in cells. In cancer, miRNAs can function as tumor suppressors or oncogenes (15). We examined the effects of the HDACi trichostatin A (TSA) on the survival of the apoptotic-resistant MCF-7TN-R breast carcinoma cell line, as well as its effects on miRNA expression. 
Table I. microRNA microarray results for MCF-7TN-R cells treated with TSA $(10 \mu \mathrm{M})$ for $24 \mathrm{~h}$.

\begin{tabular}{|c|c|c|c|c|c|}
\hline ID & Serial no. & Average (TSA) & Average (DMSO) & $\mathrm{p}$-value & $\log \mathrm{FC}$ \\
\hline hsa-miR-215 & 990 & 498.33 & 323.67 & 0.001 & 1.46 \\
\hline hsa-miR-657 & 725 & 206.33 & 573.67 & 0.002 & -1.13 \\
\hline hsa-miR-139 & 524 & 886.33 & 783.67 & 0.003 & 0.88 \\
\hline hsa-miR-155 & 544 & 192.67 & 176.33 & 0.005 & 0.73 \\
\hline hsa-miR-146b & 1501 & 182.67 & 178.00 & 0.005 & 0.66 \\
\hline hsa-miR-645 & 1681 & 181.33 & 519.67 & 0.006 & -1.27 \\
\hline hsa-miR-544 & 127 & 374.67 & 305.67 & 0.006 & 1.01 \\
\hline hsa-miR-194 & 1541 & 362.67 & 319.67 & 0.007 & 0.95 \\
\hline hsa-miR-628 & 696 & 190.67 & 371.67 & 0.007 & -0.60 \\
\hline hsa-miR-144 & 1498 & 148.00 & 115.33 & 0.008 & 0.94 \\
\hline hsa-miR-144 & 530 & 154.67 & 110.67 & 0.008 & 1.10 \\
\hline hsa-miR-559 & 1112 & 128.67 & 111.67 & 0.008 & 0.74 \\
\hline hsa-miR-128b & 511 & 868.00 & 905.00 & 0.009 & 0.62 \\
\hline hsa-miR-143 & 529 & 204.67 & 143.67 & 0.009 & 1.13 \\
\hline hsa-miR-568 & 1121 & 145.67 & 130.33 & 0.009 & 0.74 \\
\hline hsa-miR-769-5p & 744 & 230.33 & 502.33 & 0.010 & -0.69 \\
\hline hsa-miR-1 & 1461 & 226.00 & 130.33 & 0.010 & 1.48 \\
\hline hsa-miR-497 & 645 & 296.67 & 639.67 & 0.011 & -0.66 \\
\hline hsa-miR-632 & 1668 & 217.33 & 603.00 & 0.012 & -1.12 \\
\hline hsa-miR-767-5p & 1708 & 178.00 & 392.67 & 0.012 & -0.73 \\
\hline hsa-miR-512-3p & 660 & 155.33 & 362.67 & 0.013 & -0.82 \\
\hline hsa-miR-191* & 1537 & 206.67 & 138.33 & 0.014 & 1.25 \\
\hline hsa-miR-191* & 569 & 285.33 & 155.33 & 0.015 & 1.65 \\
\hline hsa-miR-155 & 1512 & 163.67 & 150.67 & 0.015 & 0.70 \\
\hline hsa-miR-613 & 1649 & 246.00 & 624.33 & 0.016 & -0.93 \\
\hline hsa-miR-202* & 977 & 479.33 & 378.00 & 0.016 & 1.05 \\
\hline hsa-miR-636 & 704 & 226.67 & 705.33 & 0.018 & -1.20 \\
\hline hsa-miR-486 & 1600 & 192.00 & 129.67 & 0.019 & 1.21 \\
\hline hsa-miR-622 & 1658 & 181.33 & 401.67 & 0.019 & -0.79 \\
\hline hsa-miR-215 & 22 & 469.00 & 289.00 & 0.020 & 1.61 \\
\hline hsa-miR-22 & 27 & 1007.33 & 568.33 & 0.021 & 1.82 \\
\hline hsa-miR-875-5p & 903 & 139.67 & 103.33 & 0.024 & 0.99 \\
\hline hsa-miR-620 & 1656 & 210.00 & 127.33 & 0.024 & 1.36 \\
\hline hsa-miR-370 & 581 & 1265.67 & 1152.67 & 0.026 & 0.88 \\
\hline hsa-miR-200c & 7 & 272.67 & 278.00 & 0.026 & 0.60 \\
\hline hsa-miR-638 & 706 & 1096.67 & 1021.00 & 0.026 & 0.85 \\
\hline hsa-miR-630 & 1666 & 140.33 & 129.00 & 0.028 & 0.71 \\
\hline hsa-miR-208 & 14 & 191.33 & 168.67 & 0.028 & 0.74 \\
\hline hsa-miR-526c & 121 & 321.33 & 215.33 & 0.028 & 1.27 \\
\hline hsa-miR-643 & 711 & 138.33 & 268.33 & 0.029 & -0.61 \\
\hline hsa-miR-651 & 719 & 142.33 & 332.67 & 0.029 & -0.84 \\
\hline hsa-miR-149 & 537 & 733.67 & 711.00 & 0.031 & 0.71 \\
\hline hsa-miR-589 & 1880 & 150.67 & 137.00 & 0.032 & 0.77 \\
\hline hsa-miR-768-3p & 1709 & 994.33 & 1006.00 & 0.033 & 0.79 \\
\hline hsa-miR-22 & 995 & 935.67 & 635.00 & 0.035 & 1.65 \\
\hline hsa-miR-627 & 1663 & 133.67 & 102.00 & 0.035 & 0.96 \\
\hline hsa-miR-450 & 1588 & 270.67 & 571.33 & 0.036 & -0.63 \\
\hline hsa-miR-620 & 688 & 198.33 & 136.67 & 0.036 & 1.17 \\
\hline hsa-miR-211 & 987 & 618.67 & 578.33 & 0.037 & 0.83 \\
\hline hsa-miR-346 & 84 & 625.33 & 604.67 & 0.041 & 0.77 \\
\hline
\end{tabular}


Table I. Continued.

\begin{tabular}{lcccrr}
\hline ID & Serial no. & Average (TSA) & Average (DMSO) & p-value & $\operatorname{logFC}$ \\
\hline hsa-miR-1 & 493 & 256.00 & 184.67 & 0.041 & 1.11 \\
hsa-miR-607 & 191 & 171.33 & 155.33 & 0.041 & 0.70 \\
hsa-miR-153 & 1509 & 145.67 & 124.00 & 0.041 & 0.85 \\
hsa-miR-621 & 1657 & 277.00 & 196.00 & 0.042 & 1.10 \\
hsa-miR-668 & 1700 & 233.33 & 538.67 & 0.043 & -0.74 \\
hsa-miR-607 & 1159 & 105.33 & 254.00 & 0.043 & -1.04 \\
hsa-miR-129 & 1480 & 533.33 & 495.00 & 0.045 & 0.82 \\
hsa-miR-335 & 76 & 175.67 & 134.00 & 0.045 & 0.96 \\
hsa-miR-640 & 1676 & 188.67 & 447.00 & 0.047 & -0.80 \\
hsa-miR-524* & 116 & 256.00 & 243.00 & 0.048 & 0.61 \\
hsa-miR-663 & 731 & 681.33 & 757.67 & 0.049 & 0.60 \\
\hline
\end{tabular}

\section{Materials and methods}

Cell generation and culture. The apoptotic-resistant MCF-7TN-R cells were derived from MCF-7 cells grown in increasing concentrations of tumor necrosis factor $\alpha$ (TNF $\alpha)$ until resistance was established. Cells were maintained in Dulbecco's modified Eagle's medium (DMEM) (Gibco) supplemented with $10 \%$ fetal bovine serum (FBS) (10\% DMEM). The detailed methods are described by Weldon et al (16).

Clonogenicity assay. Colony survival assays were performed as previously published (17). Briefly, cells were cultured in $10 \%$ FBS-DMEM media. Cells were seeded at a density of 2,000 cells/well in $2 \mathrm{ml}$ of media in 6-well plates. Cells were allowed to adhere overnight at $37^{\circ} \mathrm{C}$ and treated on the following day with vehicle (DMSO) or TSA $(0.1,1,10 \mu \mathrm{M})$. After 10 days, media was removed and the cells were fixed with gluteraldehyde. Cells were stained with crystal violet $(0.1 \%$ in $20 \%$ methanol) for visualization. Colonies $>50$ cells were manually counted and treatments normalized to vehicle control. Assays were run in quadruplicate with internal duplicates.

microRNA microarray analysis. MCF-7TN-R cells were plated at a density of $2 \times 10^{6}$ cells in $25 \mathrm{~cm}^{2}$ flasks in normal culture media (DMEM media supplemented with $5 \%$ FBS, $1 \%$ penicillin/streptomycin, $1 \%$ essential amino acids, $1 \%$ non-essential amino acids and $1 \%$ sodium pyruvate) and allowed to adhere overnight at $37^{\circ} \mathrm{C}, 5 \% \mathrm{CO}_{2}$ and air. The following day the media was changed to phenol red-free media (supplemented as above) and 5\% charcoal-stripped serum was substituted for the 5\% FBS. Cells were treated with TSA $(10 \mu \mathrm{M})$ or DMSO for $24 \mathrm{~h}$. Cells were harvested in PBS, collected by centrifugation, and total RNA extracted using the miRNeasy kit (Qiagen) according to manufacturer's protocol. Enrichment for miRNA was not performed. Quantity and quality of RNA was determined by absorbance $(260,280 \mathrm{~nm})$, and $5 \mu \mathrm{g}$ total RNA was used for microarray analysis. Microarray analysis was performed as we have previously described (18). Briefly, a custom microarray (19) was used to determine miRNA expression, using three biological replicates for each condition ( \pm TSA). Low intensity probes (signal $<100$ in more than half samples) were excluded from the analysis. Raw data was log-transformed and normalized by IQR. Clustering of miRNA expression data was performed using CLUSTER (20), with filtering to remove inconsistencies between replicates. For clustering, we first logtransformed the data and median-centered the array and genes, followed by average linkage clustering. Clustering results were visualized by TreeView (http://rana.lbl.gov/EisenSoftware. htm). Full array data is shown in Table I.

Statistical analyses. Colony assays were analyzed by one-way ANOVA with the Tukey's post-test (Graph Pad Prism V.4); $\mathrm{p}<0.05$ was considered to indicate statistically significant differences. The Student's t-test was performed to evaluate the statistical significance of the cluster selection. For microRNA microarray data, the Welch's t-test was performed for each probe using their normalized signals, with p-values $<0.05$ considered significant as previously described (21).

\section{Results}

TSA inhibits drug-resistant breast cancer cell clonogenic survival. We have previously described the generation of the MCF-7TN-R cells (16) which have acquired resistance to TNF $\alpha$ - and TRAIL-induced cell death. These cells have been characterized as highly aggressive and metastatic, and have been developed as a model system of chemoresistant breast carcinoma $(22,23)$. To determine the effects of HDACi on apoptotic and clonogenic survival, MCF-7TN-R cells were treated with varying concentrations of TSA $(0.1,1$ and $10 \mu \mathrm{M})$ or vehicle control (DMSO) for 10 days. MCF-7TN-R cells treated with TSA at $10 \mu \mathrm{M}$ for 10 days demonstrated a decrease $(\mathrm{p}<0.01)$ in colony formation compared to vehicle-treated cells (62.37 $\pm 6.45 \%$, Fig. 1).

TSA induces microRNA expression in MCF-7TN-R cells indicative of tumor suppressive and anti-metastatic effects. In human breast cancer, we and others have shown that specific miRNAs are significantly altered, as compared with normal breast tissue (21,24-26). Altered expression of specific miRNAs has been associated with poor prognosis (27), as well as breast cancer initiation, invasion and metastasis (28-31). 


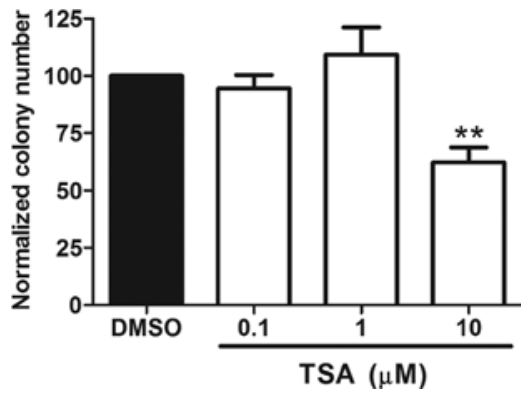

Figure 1. TSA suppression of MCF-7TN-R cell clonogenic survival. MCF$7 \mathrm{TN}-\mathrm{R}$ cells were plated $(2,000$ cells/well) in 10\% DMEM in 6-well plates and allowed to adhere overnight. Twenty-four hours later the cells were treated with vehicle (DMSO) or TSA $(0.1,1,10 \mu \mathrm{M})$ for 10 days. Colonies of $\geq 50$ cells were counted as positive. Bars represent mean percentage clonogenic survival normalized to DMSO control cells \pm SEM. $\left({ }^{* *} \mathrm{p}<0.01\right)$

The importance of miRNAs in these advanced breast cancer phenotypes raises the question of their further involvement in apoptotic resistance. Furthermore, based on the above result demonstrating MCF-7TN-R growth-inhibition by TSA, we performed microRNA microarray analysis of MCF-7TN-R cells after treatment with TSA (10 $\mu \mathrm{M}$ for $24 \mathrm{~h})$. As shown in Fig. 2, a number of microRNA expression changes were observed. In addition, the three biological replicates from vehicle-treated MCF-7TN-R clustered together and separately from TSA-treated cells, demonstrating high reproducibility between biological repeats as well as differential microRNA expression induced by TSA. Of the microRNAs significantly altered by HDACi treatment, 22 were up-regulated (Table II) and 10 were down-regulated (Table III). Their predicted (TargetScan and miRanda) or confirmed gene targets are provided.

\section{Discussion}

Drug resistance, acquired or de novo, remains a major obstacle in the treatment of cancer (1). Progression to resistance represents one of the hallmarks of aggressive carcinomas with limited treatment options and poor prognoses $(2,3)$. Epigenetic therapies, including HDACi, provide a novel class of treatment for therapeutically-resistant cancer patients (32), including breast cancer (33). Here we demonstrate the ability of the HDACi TSA to suppress in vitro clonogenic survival of the apoptotically resistant MCF-7TN-R cells. This cell culture data indicates that in progressive drug resistance or recurrent breast carcinoma, the use of HDACis may exhibit greater inhibitory effects on tumor cell survival. Numerous studies have analyzed gene expression changes in response to $\mathrm{HDACi}$, with the goal of defining specific mechanisms of their anticancer activity (34). Recent studies have also demonstrated the regulation of microRNA expression changes in breast and other cancer cells treated with HDACi alone $(9,10,13,35)$, or in combination with DNMTi (11,36-38). Overall, these studies revealed microRNA expression profiles suggestive of a less aggressive and more tumor-suppressive phenotype after treatment with epigenetic therapies. Consistent with those studies, our microarray results revealed that many of the microRNAs that were significantly up-regulated (Table II) following TSA treatment (compared to control) have been characterized as having tumor suppressive

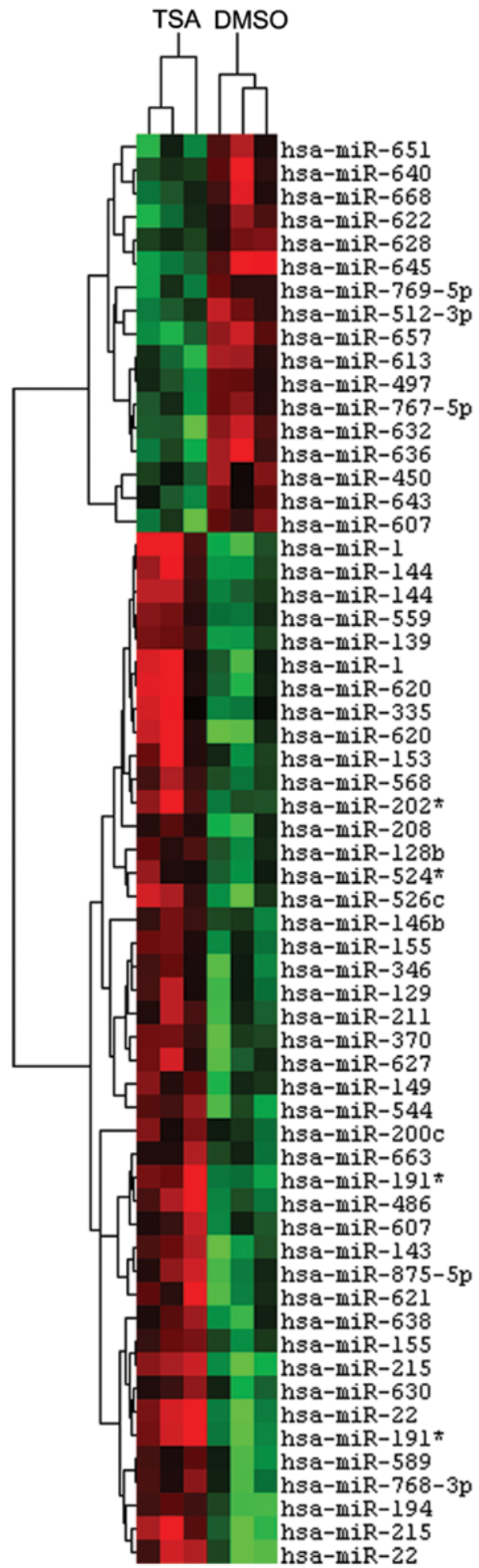

Figure 2. TSA regulation of microRNA expression in MCF-7TN-R. Heatmap of microRNA changes induced by treatment with TSA $(10 \mu \mathrm{M})$ after $24 \mathrm{~h}$ in MCF-7TN-R cells. microRNAs demonstrating statistically significant changes in expression are shown $(\mathrm{p}<0.01)$. Green indicates down-regulated expression and red indicates up-regulated expression of microRNAs. Individual samples are represented in columns while specific microRNAs are represented by rows as labeled.

(miR-1, miR-143, miR-144, miR-191*, miR-202*, miR-486, miR-559), anti-migration/anti-metastasis (miR-22, miR-139, miR-194, miR-335), or anti-EMT (miR-215) roles in cancer. 
Table II. Up-regulated miRNA following TSA treatment.

\begin{tabular}{|c|c|c|c|c|}
\hline microRNA & Mean fold change & p-value & Description & Gene targets (ref.) \\
\hline hsa-miR-1 & 2.44 & $<0.05$ & Tumor suppressor & cMET (39), TAGLN2 $(40,41)$ \\
\hline hsa-miR-22 & 2.69 & $<0.05$ & Anti-migration, cell cycle arrest & MYCBP, MAX \\
\hline hsa-miR-139 & 1.61 & $<0.05$ & Anti-metastatic, tumor suppressor & ROCK2 (29), CDK6* , HOXB2* \\
\hline hsa-miR-143 & 1.94 & $<0.05$ & Tumor suppressor & KRAS (42), BCL2 (43) \\
\hline hsa-miR-144 & 1.97 & $<0.05$ & Tumor suppressor & Notch1 (44) \\
\hline hsa-miR-153 & 1.70 & $<0.05$ & Tumor suppressor & BCL2 (45) \\
\hline hsa-miR-155 & 1.53 & $<0.01$ & OncomiR & $\begin{array}{l}\text { FOXO3A (46), SOCS1 (47), } \\
\text { FADD and IKKE (48) }\end{array}$ \\
\hline hsa-miR-191* & 2.51 & $<0.05$ & Tumor suppressor & $\mathrm{SPEN}^{*}$ \\
\hline hsa-miR-194 & 1.70 & $<0.01$ & Tumor suppressor, anti-metastatic & CDH2, HBEGF, RAC1 and IGF1R (49) \\
\hline hsa-miR-215 & 2.26 & $<0.01$ & Anti-EMT, cell cycle arrest & ZEB $1 / 2(50)$ \\
\hline hsa-miR-202* & 1.82 & $<0.05$ & Tumor suppressor & TGFBR2 ${ }^{*}$, ROCK $1^{*}$ \\
\hline hsa-miR-335 & 1.83 & $<0.05$ & $\begin{array}{l}\text { Tumor suppressor, cell cycle arrest, } \\
\text { metastasis suppressor }\end{array}$ & RB1/p105 (51), SOX4 and TNC (28) \\
\hline hsa-miR-486 & 1.97 & $<0.05$ & Tumor suppressor & CD40 (52) \\
\hline hsa-miR-526c & 2.14 & $<0.05$ & & \\
\hline hsa-miR-544 & 1.74 & $<0.01$ & & \\
\hline hsa-miR-559 & 1.61 & $<0.05$ & Tumor suppressor & ERBB2 (53) \\
\hline hsa-miR-568 & 1.59 & $<0.05$ & & \\
\hline hsa-miR-620 & 2.31 & $<0.05$ & & \\
\hline hsa-miR-627 & 1.93 & $<0.05$ & & \\
\hline hsa-miR-638 & 1.55 & $<0.01$ & & \\
\hline hsa-miR-641 & 2.02 & $<0.05$ & & \\
\hline hsa-miR-888 & 1.76 & $<0.05$ & & \\
\hline
\end{tabular}

*Putative targets as indicated by TargetScan and miRanda.

Table III. Down-regulated miRNA following TSA treatment.

\begin{tabular}{|c|c|c|c|c|}
\hline microRNA & Mean fold change & p-value & Description (ref.) & Gene targets (ref.) \\
\hline hsa-miR-500 & -1.90 & $<0.05$ & OncomiR (54) & \\
\hline hsa-miR-512-3p & -1.59 & $<0.05$ & & cFLIP (55) \\
\hline hsa-miR-607 & -1.68 & $<0.05$ & & \\
\hline hsa-miR-613 & -1.69 & $<0.05$ & & LXR (56) \\
\hline hsa-miR-622 & -1.57 & $<0.05$ & & \\
\hline hsa-miR-632 & -1.86 & $<0.01$ & & \\
\hline hsa-miR-636 & -2.00 & $<0.05$ & & \\
\hline hsa-miR-645 & -2.03 & $<0.01$ & OncomiR (57) & \\
\hline hsa-miR-651 & -1.60 & $<0.05$ & & \\
\hline hsa-miR-657 & -1.91 & $<0.01$ & & IGF2R (58) \\
\hline
\end{tabular}

Only one known oncomiR, miR-155, was found to be increased following TSA treatment, but with a mean fold change of 1.53 compared to control, this was the lowest change observed, although statistically significant. Of the microRNAs identified as significantly decreased (Table III) following TSA treatment (compared to control), two have been identified as oncomiRs (miR-500, miR-645) and three others have confirmed targets involved in tumorigenesis (miR-512-3p, miR-613, miR-657). Taken together, these data indicate that HDACi treatment may promote an anti-tumor microRNA expression profile in the apoptotically resistant cell line MCF-7TN-R, providing novel therapeutic targets for the treatment of drug resistant breast cancer. 


\section{Acknowledgements}

This research was supported by The Department of Defense Breast Cancer Research Program BC085426 (B.M. CollinsBurow); The National Institutes of Health/National Center for Research Resources P20RR020152 (B.M. Collins-Burow); The Integrated Cancer Biology Program: Centers for Cancer Systems Biology NIH/NCI U54CA113001 (K. Nephew); and The Walther Cancer Foundation, Indianapolis, IN (S.Y. Nam). The funders did not have any involvement in study design; the collection, analysis, or interpretation of the data; the writing of the manuscript; or the decision to submit the manuscript for publication.

\section{References}

1. Clarke R, Liu MC, Bouker KB, et al: Antiestrogen resistance in breast cancer and the role of estrogen receptor signaling. Oncogene 22: 7316-7339, 2003.

2. Garcia M, Derocq D, Freiss G and Rochefort H: Activation of estrogen receptor transfected into a receptor-negative breast cancer cell line decreases the metastatic and invasive potential of the cells. Proc Natl Acad Sci USA 89: 11538-11542, 1992.

3. van Agthoven T, Sieuwerts AM, Meijer-van Gelder ME, et al: Relevance of breast cancer antiestrogen resistance genes in human breast cancer progression and tamoxifen resistance. J Clin Oncol 27: 542-549, 2009.

4. Ting AH, McGarvey KM and Baylin SB: The cancer epigenome-components and functional correlates. Genes Dev 20: 3215-3231, 2006.

5. Lo PK and Sukumar S: Epigenomics and breast cancer. Pharmacogenomics 9: 1879-1902, 2008.

6. Sabnis GJ, Goloubeva O, Chumsri S, Nguyen N, Sukumar S and Brodie AM: Functional activation of the estrogen receptor-alpha and aromatase by the HDAC inhibitor entinostat sensitizes ER-negative tumors to letrozole. Cancer Res 71: 1893-1903, 2011.

7. Boumber Y and Issa JP: Epigenetics in cancer: what's the future? Oncology (Williston Park) 25: 220-226, 228, 2011.

8. Wilkes G: Histone deacetylase inhibitors. Oncology (Williston Park) 21: 39-40, 2007.

9. Zhang S, Cai X, Huang F, Zhong W and Yu Z: Effect of trichostatin a on viability and microRNA expression in human pancreatic cancer cell line BxPC-3. Exp Oncol 30: 265-268, 2008

10. Shin S, Lee EM, Cha HJ, et al: MicroRNAs that respond to histone deacetylase inhibitor SAHA and p53 in HCT116 human colon carcinoma cells. Int J Oncol 35: 1343-1352, 2009.

11. Bandres E, Agirre X, Bitarte N, et al: Epigenetic regulation of microRNA expression in colorectal cancer. Int J Cancer 125 : 2737-2743, 2009.

12. Saito Y, Suzuki H, Tsugawa H, et al: Chromatin remodeling at Alu repeats by epigenetic treatment activates silenced microRNA512-5p with downregulation of Mcl-1 in human gastric cancer cells. Oncogene 28: 2738-2744, 2009.

13. Scott GK, Mattie MD, Berger CE, Benz SC and Benz CC: Rapid alteration of microRNA levels by histone deacetylase inhibition. Cancer Res 66: 1277-1281, 2006.

14. Ambros V: microRNAs: tiny regulators with great potential. Cell 107: 823-826, 2001

15. Shenouda SK and Alahari SK: MicroRNA function in cancer: oncogene or a tumor suppressor? Cancer Metastasis Rev 28: 369-378, 2009

16. Weldon CB, Parker AP, Patten D, et al: Sensitization of apoptotically-resistant breast carcinoma cells to TNF and TRAIL by inhibition of p38 mitogen-activated protein kinase signaling. Int J Oncol 24: 1473-1480, 2004

17. Zhou C, Nitschke AM, Xiong W, et al: Proteomic analysis of tumor necrosis factor-alpha resistant human breast cancer cells reveals a MEK5/Erk5-mediated epithelial-mesenchymal transition phenotype. Breast Cancer Res 10: R105, 2008.

18. Xin F, Li M, Balch C, et al: Computational analysis of microRNA profiles and their target genes suggests significant involvement in breast cancer antiestrogen resistance. Bioinformatics 25 : 430-434, 2009
19. Thomson JM, Parker J, Perou CM and Hammond SM: A custom microarray platform for analysis of microRNA gene expression. Nat Methods 1: 47-53, 2004.

20. Eisen MB, Spellman PT, Brown PO and Botstein D: Cluster analysis and display of genome-wide expression patterns. Proc Natl Acad Sci USA 95: 14863-14868, 1998.

21. Di Leva G, Gasparini P, Piovan C, et al: MicroRNA cluster 221-222 and estrogen receptor alpha interactions in breast cancer. J Natl Cancer Inst 102: 706-721, 2010.

22. Antoon JW, Liu J, Gestaut MM, Burow ME, Beckman BS and Foroozesh M: Design, synthesis, and biological activity of a family of novel ceramide analogues in chemoresistant breast cancer cells. J Med Chem 52: 5748-5752, 2009.

23. Meacham WD, Antoon JW, Burow ME, Struckhoff AP and Beckman BS: Sphingolipids as determinants of apoptosis and chemoresistance in the MCF-7 cell model system. Exp Biol Med (Maywood) 234: 1253-1263, 2009.

24. Foekens JA, Sieuwerts AM, Smid M, et al: Four miRNAs associated with aggressiveness of lymph node-negative, estrogen receptor-positive human breast cancer. Proc Natl Acad Sci USA 105: 13021-13026, 2008.

25. Iorio MV, Ferracin M, Liu CG, et al: MicroRNA gene expression deregulation in human breast cancer. Cancer Res 65: 7065-7070, 2005.

26. Rao X, Di Leva G, Li M, et al: MicroRNA-221/222 confers breast cancer fulvestrant resistance by regulating multiple signaling pathways. Oncogene 30: 1082-1097, 2010.

27. Nana-Sinkam SP and Croce CM: MicroRNAs as therapeutic targets in cancer. Transl Res 157: 216-225, 2011.

28. Tavazoie SF, Alarcon C, Oskarsson T, et al: Endogenous human microRNAs that suppress breast cancer metastasis. Nature 451: $147-152,2008$.

29. Wong CC, Wong CM, Tung EK, et al: The microRNA miR-139 suppresses metastasis and progression of hepatocellular carcinoma by down-regulating Rho-kinase 2. Gastroenterology 140: 322-331, 2011.

30. Ma L, Teruya-Feldstein $J$ and Weinberg RA: Tumour invasion and metastasis initiated by microRNA-10b in breast cancer. Nature 449: 682-688, 2007.

31. Ma L and Weinberg RA: MicroRNAs in malignant progression. Cell Cycle 7: 570-572, 2008.

32. Atadja PW: HDAC inhibitors and cancer therapy. Prog Drug Res 67: 175-195, 2011.

33. Munster PN, Thurn KT, Thomas S, et al: A phase II study of the histone deacetylase inhibitor vorinostat combined with tamoxifen for the treatment of patients with hormone therapyresistant breast cancer. Br J Cancer 104: 1828-1835, 2011.

34. Shankar S and Srivastava RK: Histone deacetylase inhibitors: mechanisms and clinical significance in cancer: HDAC inhibitorinduced apoptosis. Adv Exp Med Biol 615: 261-298, 2008.

35. Lee EM, Shin S, Cha HJ, et al: Suberoylanilide hydroxamic acid (SAHA) changes microRNA expression profiles in A549 human non-small cell lung cancer cells. Int J Mol Med 24: 45-50, 2009.

36. Saito Y and Jones PA: Epigenetic activation of tumor suppressor microRNAs in human cancer cells. Cell Cycle 5: 2220-2222, 2006.

37. Saito Y,Liang G, Egger G, et al: Specific activation of microRNA127 with downregulation of the proto-oncogene BCL6 by chromatin-modifying drugs in human cancer cells. Cancer Cell 9: 435-443, 2006.

38. Lujambio A and Esteller M: CpG island hypermethylation of tumor suppressor microRNAs in human cancer. Cell Cycle 6: 1455-1459, 2007.

39. Yan D, Dong Xda E, Chen X, et al: MicroRNA-1/206 targets c-Met and inhibits rhabdomyosarcoma development. J Biol Chem 284: 29596-29604, 2009.

40. Nohata N, Sone Y, Hanazawa T, et al: miR-1 as a tumor suppressive microRNA targeting TAGLN2 in head and neck squamous cell carcinoma. Oncotarget 2: 29-42, 2011.

41. Yoshino H, Chiyomaru T, Enokida H, et al: The tumoursuppressive function of miR-1 and miR-133a targeting TAGLN2 in bladder cancer. Br J Cancer 104: 808-818, 2011.

42. Xu B, Niu X, Zhang X, et al: miR-143 decreases prostate cancer cells proliferation and migration and enhances their sensitivity to docetaxel through suppression of KRAS. Mol Cell Biochem 350: 207-213, 2011.

43. Zhang H, Cai X, Wang Y, Tang H, Tong D and Ji F: microRNA143, down-regulated in osteosarcoma, promotes apoptosis and suppresses tumorigenicity by targeting Bcl-2. Oncol Rep 24: $1363-1369,2010$ 
44. Sureban SM, May R, Lightfoot S, et al: DCAMKL-1 regulates epithelial-mesenchymal transition in human pancreatic cells through a miR-200a-dependent mechanism. Cancer Res 71: 2328-2338, 2011

45. Xu J, Liao X and Wong C: Downregulation of B-cell lymphoma 2 and myeloid cell leukemia sequence 1 by microRNA 153 induce apoptosis in a glioblastoma cell line DBTRG-05MG. Int J Cancer 126: 1029-1035, 2010

46. Kong W, He L, Coppola M, et al: MicroRNA-155 regulates cell survival, growth, and chemosensitivity by targeting FOXO3a in breast cancer. J Biol Chem 285: 17869-17879, 2010.

47. Jiang S, Zhang HW, Lu MH, et al: MicroRNA-155 functions as an OncomiR in breast cancer by targeting the suppressor of cytokine signaling 1 gene. Cancer Res 70: 3119-3127, 2010.

48. Tili E, Michaille JJ, Cimino A, et al: Modulation of miR-155 and miR-125b levels following lipopolysaccharide/TNF-alpha stimulation and their possible roles in regulating the response to endotoxin shock. J Immunol 179: 5082-5089, 2007.

49. Meng Z, Fu X, Chen X, et al: miR-194 is a marker of hepatic epithelial cells and suppresses metastasis of liver cancer cells in mice. Hepatology 52: 2148-2157, 2010.

50. Kato M, Zhang J, Wang M, et al: MicroRNA-192 in diabetic kidney glomeruli and its function in TGF-beta-induced collagen expression via inhibition of E-box repressors. Proc Natl Acad Sci USA 104: 3432-3437, 2007.

51. Scarola M, Schoeftner S, Schneider C and Benetti R: miR-335 directly targets $\mathrm{Rb} 1(\mathrm{pRb} / \mathrm{p} 105)$ in a proximal connection to p53-dependent stress response. Cancer Res 70: 6925-6933, 2010.
52. Mees ST, Mardin WA, Sielker S, et al: Involvement of CD40 targeting miR-224 and miR-486 on the progression of pancreatic ductal adenocarcinomas. Ann Surg Oncol 16: 2339-2350, 2009.

53. Chen H, Sun JG, Cao XW, et al: Preliminary validation of ERBB2 expression regulated by miR-548d-3p and miR-559. Biochem Biophys Res Commun 385: 596-600, 2009.

54. Yamamoto Y, Kosaka N, Tanaka M, et al: MicroRNA-500 as a potential diagnostic marker for hepatocellular carcinoma. Biomarkers 14: 529-538, 2009.

55. Chen F, Zhu HH, Zhou LF, Wu SS, Wang J and Chen Z: Inhibition of c-FLIP expression by miR-512-3p contributes to taxol-induced apoptosis in hepatocellular carcinoma cells. Oncol Rep 23: 1457-1462, 2010.

56. Ou Z, Wada T, Gramignoli R, et al: MicroRNA hsa-miR-613 targets the human LXR(alpha) gene and mediates a feedback loop of LXR(alpha) autoregulation. Mol Endocrinol 25: 584-596, 2011.

57. Shih KK, Qin LX, Tanner EJ, et al: A microRNA survival signature (MiSS) for advanced ovarian cancer. Gynecol Oncol 121: 444-450, 2011.

58. Lv K, Guo Y, Zhang Y, Wang K, Jia Y and Sun S: Allele-specific targeting of hsa-miR-657 to human IGF2R creates a potential mechanism underlying the association of ACAA-insertion/ deletion polymorphism with type 2 diabetes. Biochem Biophys Res Commun 374: 101-105, 2008. 